\title{
TÉCNICA, TECNOLOGIA E DILEMAS ÉTICOS
}

Marconi Pequeno ${ }^{1}$

\section{Resumo:}

A técnica (téchnē) pensada pelos filósofos gregos antigos representava o fazer necessário baseado na aptidão e na destreza. Ela manifestava um tipo de virtude intelectual destinada à produção de algo essencial ao bem-estar dos cidadãos e útil ao desenvolvimento da pólis. Esse seu emprego foi desvirtuado a partir da modernidade, momento em que a técnica foi incorporada pela tecnologia até atingir seu paroxismo no mundo contemporâneo sob a forma de tecnocracia, domínio da natureza e controle das pessoas. Tal evento gerou inúmeros dilemas e encruzilhadas morais que animam hoje o debate sobre as possibilidades, o alcance e os limites da razão instrumental na vida dos indivíduos. Este artigo trata das transformações sofridas pela técnica, da sua incorporação por parte das tecnociências, dos seus avanços e conquistas, e, finalmente, dos desafios éticos suscitados por suas diversas aplicações em nosso contexto societário.

Palavras-chave: Técnica. Tecnologia. Dilemas éticos.

\section{TECHNIQUE, TECHNOLOGY AND ETHICAL DILEMMAS}

\begin{abstract}
:
The technique (téchnē) thought by the ancient Greeks philosophers represented the necessary doing based on ability and dexterity. It manifested a type of intellectual virtue aimed at producing something essential for the well-being of citizens and useful to the development of the pólis. Its usage has been distorted since modernity, once the technique was incorporated by technology, reaching its paroxysm in the contemporary world in the form of technocracy, mastery of nature and control of people. Such an event generated countless dilemmas and moral crossroads that nowadays encourage the debate about the possibilities, range and limits of the instrumental reason in the lives of individuals. This article addresses the transformations undergone by the technique, its incorporation by technosciences, its advances and achievements, and, finally, the ethical challenges brought by its various applications in our social context.
\end{abstract}

Keywords: Technique. Technology. Ethical dilemmas.

A técnica foi originariamente concebida como a possibilidade humana de transformar a natureza com vistas à realização de fins. A palavra técnica origina-se do grego téchnē e indica um conhecimento específico destinado à produção de algo. A técnica aparece, assim, como um tipo de habilidade ou destreza e, em razão disso, ela se associa à arte. Para os gregos, a retórica, a medicina, a música e a política, por exemplo, seriam ambas as coisas.

De fato, Platão, em sua celébre $A$ república, considerava a política como a arte e a técnica de bem governar. $\mathrm{O}$ exercício da governança exigiria não apenas conhecimento, mas também aptidão e perícia. Aristóteles, em seguida, associa a téchnē à gnosis (virtudes intelectuais/dianoéticas) diferindo ambas das virtudes éticas, cujo substrato é a phronesis (sabedoria prática). Assim, enquanto a téchnē se impõe como uma capacidade para o criar, a

1 Doutor em Filosofia pela Université de Strasbourg. Professor da Universidade Federal da Paraíba. E-mail: mpequeno@bol.com.br 
phronesis se revela como uma disposição para o agir com vistas ao exercício da excelência (areté) ou à conquista da felicidade (eudaimonia). A virtude ética depende, assim, do caráter do indivíduo, enquanto a téchnē decorre de sua aptidão para fazer surgir o que se afigura útil e necessário.

Aristóteles, nessa mesma perspectiva, faz uma distinção entre téchnē, cujo fim lhe é extrínseco, posto que visa realizar ou produzir algo, e a episteme, cuja finalidade é intrínseca ao indivíduo, haja vista que o conhecimento, como vimos, aparece como uma modalidade de virtude intelectual. Porém, a técnica que, como preconizava o referido filósofo, representava uma espécie de extensão humana de um processo natural, aos poucos foi se tornando o motor da desumanização do próprio homem. Isso ocorreu, sobretudo, por meio do seu desenraizamento do mundo natural e também do controle do seu viver. Assim, tudo se passa como se a técnica tivesse adquirido vida própria ou autonomia pela via da automação tecnológica. Em outras palavras, a técnica atingiu o seu paroxismo com a emergência da tecnologia. Em face desse novo cenário, de que maneira podemos associar a técnica à tecnologia ou ainda como é possível hoje diferenciá-las e pensar a relação homem-técnicatecnologia?

Ora, do ponto de vista etimológico, a tecnologia significa o próprio "dizer da técnica", ou seja, o modo como ela é organizada, sistematizada e revelada. De fato, quando pensamos na tecnologia, somos conduzidos a um processo mais elaborado que seria responsável pela criação e pelo desenvolvimento de inúmeros produtos, engenhos e artefatos. A tecnologia poderia ser descrita como o ponto de culminação da técnica. Assim, ao contrário da tecnologia, a técnica não implica necessariamente em controle e domínio do homem sobre a natureza. Ela, como ocorria entre os gregos da Antiguidade clássica, estava associada ao fazer criativo, à produção do necessário e ao exercício das aptidões e capacidades humanas.

O fato é que, com o surgimento das ciências modernas, a técnica passa a fomentar as tecnologias de controle e de domínio da natureza. Desse modo, o homem que se utilizava da técnica passou, a partir da modernidade, a ser por ela dominado. Ocorre, a partir daí, o que se pode chamar de domínio tecnológico dos nossos espaços vitais. Com efeito, enquanto na antiga Grécia a técnica aparecia como um produto da capacidade humana de fazer ou produzir (homo faber), com a modernidade esse mesmo homem, pouco a pouco, foi se tornando cativo do próprio poder da técnica em sua idade tecnológica (homo tecnologicus).

Essa potência de controle é o corolário do famoso lema expresso pelo pintor expressionista espanhol Francisco Goya, no final do século XVIII, em uma de suas gravuras:

\begin{tabular}{|l|l|l|l|l|}
\hline Q Rovista Qialectus & Ano 9 & n. 17 & Maio - Agosto 2020 & p.39-50 \\
\hline
\end{tabular}


"O sono da razão produz monstros"2. A razão, em seu vigoroso despertar, passou a ditar o ritmo do progresso humano e do próprio percurso da civilização ocidental. Com isso, a técnica, em seu formato tecnocientífico, assumiu um papel de centralidade nas sociedades modernas. Eis por que a técnica e sua forma mais elaborada de expressão, a tecnologia, tornaram-se onipresentes em nosso contexto societário. $\mathrm{O}$ alcance e a amplitude desse poder geraram também inúmeros problemas axiológicos e dilemas éticos a serem enfrentados em nosso tempo.

Antes de realizar um exame de tais obstáculos e encruzilhada, convém reconhecer que o problema não se encontra na técnica em si ou na tecnociência que a incorpora, mas na tecnolatria, no fanatismo tecnocrático e na tecnização das formas de vida. $\mathrm{O}$ mal consiste, pois, na dependência existencial do indivíduo da tecnologia e de seus instrumentos de dominação e controle, pois o emprego excessivo ou desordenado dos seus engenhos, mesmo quando não muda a natureza do humano, interfere na sua condição e no seu modo de existir.

Isso ocorre quando constatamos que a (bio)tecnociência não apenas domina e transforma a natureza humana, mas parece também disposta a criá-la ou recriá-la. Com isso, ela passa a forjar o próprio objeto que explora (o ser humano) por meio de inúmeros procedimentos, a exemplo da clonagem, do uso de células-tronco embrionárias, da manipulação genética, da inseminação artificial, dentre outros. Eis aqui a raiz do que se pode chamar de transhumanismo, ou seja, da tentativa de se ir além do homem³ ${ }^{3}$ Isso pode ocorrer por meio da introdução de microchips nos circuitos neurais, da intervenção sobre o cérebro por meio de substâncias ou eletrodos para o controle da mente, das próteses cibernéticas empregadas na robótica e, finalmente, da inteligência artificial. Ademais, isso também pode ocorrer por meio da bionanotecnologia, que consiste em alterar elementos essenciais da natureza humana com vistas ao aprimoramento ou à melhoria do seu genótipo. Busca-se, com isso, uma interseção entre o natural e o artificial.

Assim, não obstante os seus fascinantes avanços, a biorrevolução tecnológica que, inclusive, permitiu a criação de vida em laboratório, é fonte de inquietudes existenciais e

2 O sono da razão produz monstros é o título de uma gravura do pintor expressionista espanhol Francisco Goya, que retrata justamente o que pode acontecer quando a razão adormece e, sobretudo, quando o homem se deixa conduzir por crendices e superstições. A referida gravura foi publicada no Diário de Madrid, em 1799.

3 O transhumanismo é um movimento que defende a transformação da condição humana por meio de tecnologias capazes de ampliar suas potencialidades biológicas, intelectuais e psicológicas. Busca-se, da mesma forma, eliminar os sofrimentos e as limitações causados por doenças ou pelo envelhecimento do corpo humano. Trata-se, enfim, de uma tentativa de, por meios científicos, suplantar determinados obstáculos postos pela condição natural do ser humano.

\begin{tabular}{|l|l|l|l|l|}
\hline Q Rovista Dialectus & Ano 9 & n. 17 & Maio - Agosto 2020 & p.39-50 \\
\hline
\end{tabular}


dilemas morais, haja vista que muitas dessas técnicas podem estar a serviço do eugenismo ou do ideal de perfeição humana. Com isso, os dilemas e conflitos morais se avolumam à medida que essas novas tecnologias avançam ${ }^{4}$. Isso, notadamente, gera uma tensão entre ética e técnica, entre ciência e consciência. Por isso, uma questão se impõe: qual o lugar da ética e dos valores morais numa sociedade tecnocientífica?

Essa indagação, como sabemos, não é recente. De fato, as questões éticas que envolvem a prática médica remontam ao século $\mathrm{V}$ a.C. Essa preocupação já se revela claramente nos escritos de Hipócrates, cujo Juramento traduz a tentativa de sistematização, em forma de código, das obrigações e preocupações que devem orientar a prática médica na Grécia antiga. Seguindo esse mesmo traçado, François Rabelais, no século XVI, afirmava que a ciência sem consciência não é senão a ruína da alma (cf. RABELAIS, 1950). Essa ideia foi posteriormente corroborada por diversos autores que procuraram nos alertar sobre os usos indevidos da ciência, bem como acerca de todo o seu legado deletério. Trata-se, sobretudo, de fazer despertar ou, quiçá, fortalecer a consciência moral de um novo tipo de homem no seio de uma nova civilização.

O desafio consiste, pois, em humanizar o progresso técnico-científico e a visão instrumental que o indivíduo tem do mundo, do outro e de si mesmo, uma vez que o uso inapropriado da ciência pode conspurcar a dignidade do sujeito e conduzir a um processo de degenerescência da vida em sociedade. Além disso, convém refletir acerca de como deve proceder a tecnociência para que ela nos seja útil, até porque, como preconizava Platão no Eutidemo, o fazer deve coincidir com o saber servir-se daquilo que se faz (cf. PLATÃO, 2011).

Alguns filósofos contemporâneos denunciam a hybris (desmesura) do cientificismo em sua idade tecnológica. Esse é o caso da crítica radical de Adorno e Horkheimer em sua Dialética do esclarecimento (1985), de Herbert Marcuse em sua obra A ideologia da sociedade industrial: o homem unidimensional (1982) e, de forma menos virulenta, de Jürgen Habermas, em seu texto Técnica e ciência enquanto ideologia (1980). Todas essas perspectivas se inserem no âmbito de uma teoria crítica da sociedade. Adorno, Horkheimer e Marcuse, cada um a seu modo, denunciam a tecnicização das formas de vida levada a efeito pela razão instrumental. Tal hegemonia seria um corolário do logocentrismo

4 De fato, o modelo técnico-científico passou a dominar e a dirigir as formas de vida em sociedade. Porém, somente a partir da metade do século XX o conflito entre práticas científicas e dilemas morais começou a se intensificar, acarretando uma série de preocupações e, por conseguinte, desencadeando inúmeras iniciativas visando o seu enfrentamento. Sobre tal questão, ver LADRIÈRE, 1984.

\begin{tabular}{|c|c|c|c|c|}
\hline Rovista Dialectus & Ano 9 & n. 17 & Maio - Agosto 2020 & p.39-50 \\
\hline
\end{tabular}


que atingiu o seu ponto de culminação com a modernidade. A partir daí, deu-se um vertiginoso progresso tecnológico que forjou um novo modelo de civilização calcado na concepção mecanicista do mundo e do homem. Nessa perspectiva, como posteriormente irá denunciar Habermas (1980), a técnica foi alçada à condição de ideologia e esta passou a justificar a plenipotência da razão instrumental.

Ora, como vimos, o avanço do aparato técnico-científico tem gerado inquietudes e dilemas no seio das sociedades contemporâneas. Isso porque a emergência da tecnociência ou da ciência prolongada em técnica trouxe também consigo a tecnocracia, isto é, o poder de uma técnica calcada, sobretudo, no argumento de autoridade e no veredicto dos experts ou ultraespecialistas. Nesse contexto, a tecnocracia se transformou em tecnolatria.

$\mathrm{O}$ endeusamento da técnica seria uma decorrência daquilo que Adorno e Horkheimer chamam de mitologização da razão. Assim, a racionalidade instrumental, que havia surgido para superar as crendices e superstições, aos poucos, ela mesma, foi se transformando em mito eterno e indestrutível. Soma-se a isso o fato de que o pensamento especulativo cedeu lugar ao cálculo e à razão contábil. Eis o resultado prático desse fenômeno: mais ciência e menos filosofia, mais ideologia e menos reflexão. A valorização radical do pensamento operatório e o privilégio da instrumentalização das formas de vida ainda desencadearam o que Max Weber (1982) designa de desencantamento do mundo. Isso significa que, embora a ciência seja reverenciada como força propulsora do progresso material e também como um meio de livrar o homem do obscurantismo e da indigência intelectual, o sujeito que apenas consome verdades científicas corre o risco de perder a capacidade de contemplar o universo e de se alimentar de lirismo, poesia, imaginação e fantasia. Eis o perigo representado pelo endeusamento cego da tecnociência.

$\mathrm{Na}$ esteira dessas mudanças, constatamos o surgimento daquilo que Baudrillard (1970) chama de homem maquinal. Para ele, o futuro do corpo humano é a prótese, pois a corporeidade tem passado pelo circuito da modelagem, reconfiguração, inserção e substituição de seus órgãos ou estruturas. O corpo humano cada vez mais se revela como um engenho mecânico destinado à produção e à reprodução técnica.

O frenesi produtivo e o seu corolário, o consumismo, seriam também um dos sintomas da patologia que acomete nossa época. Isso fez com que o modus vivendi fosse subjugado pelo modus operandi. Um dos indícios dessa mudança se reflete no fato prosaico de que, quando alguém pergunta quem somos, não muito raro lhe respondemos dizendo o que fazemos. Nesse caso, o que nos define é o fazer e não a estrutura fundamental do nosso eu.

\begin{tabular}{|l|l|l|l|l|}
\hline Q Rovista Qialectus & Ano 9 & n. 17 & Maio - Agosto 2020 & p.39-50 \\
\hline
\end{tabular}


Nesse sentido, o que temos ou possuímos revelaria, em última instância, quem somos. Aliado a isso, surge o culto ao supérfluo, ao descartável, à novidade. É nesse sentido que o consumismo passa a representar uma espécie de catarse existencial ou um desejo de completude que nunca se realiza. Eis o que se poderia chamar de perversão da poiesis grega, aquele fazer necessário, a arte de criar o essencial, pois hoje queremos tudo fabricar e pretendemos cada vez mais produzir.

Além de confinados nas estruturas desse novo mundo, os indivíduos passam a ser também regidos pelos valores que eles ajudam a forjar, seja na condição de vítimas ou cúmplices, haja vista que muitos acusam os outros das imposturas que eles mesmos praticam. Soma-se a isso a evidência de que o tempo e a velocidade passaram a reger as relações humanas. De fato, vive-se a vertigem da velocidade de tudo que muda o tempo todo. O futurismo de Marinetti já havia anunciado a emergência dessa nova odisseia existencial ${ }^{5}$. Vivemos, assim, sob a égide da sociedade do deslocamento contínuo e da mobilidade total ${ }^{6}$. Com efeito, precisamos fazer cada vez mais em menos tempo e isso também está na origem daquilo que se pode chamar de sociedade do cansaço. Por isso, convém indagar: para que tanta correria? A resposta sartreana seria: para nada! Afinal, como dizia Quincas Borba, personagem do romance homônimo de Machado de Assis (1982), o homem mata o tempo, mas é o tempo que o enterra. Sim, o impiedoso Cronos, mais cedo ou mais tarde, devora os seus filhos, estejam eles em repouso ou em movimento.

Soma-se a isso o emprego cada vez mais crescente das tecnologias da informação e comunicação. A revolução digital faz com que o mundo esteja ao alcance de um clique, sendo a telepresença à distância uma de suas principais características. Além disso, tais avanços têm tornado cada vez mais inefável a fronteira entre o virtual e o real. Ademais, se o mundo virtual, por um lado, pode trazer consigo a angústia da solidão, por outro, ele é capaz de fomentar o eu narcísico que se expressa por meio da singela frase: exibo-me, logo existo! Sem esquecer que tais tecnologias também têm sido usadas como mecanismos de controle dos indivíduos, exercendo, pois, uma grande influência sobre as relações humanas. Tal regulação sistemática ocorre por meio da televigilância, de câmeras onipresentes e de estruturas destinadas a vigiar e punir, como já havia denunciado Michel Foucault (1975) ao tratar do

O Manifesto Futurista foi escrito pelo poeta italiano Filippo Marinettie e divulgado, em 1909, no Jornal francês Le Figaro. Ele se configurou como um dos movimentos precursores da arte moderna. Sua principal característica consistia na defesa do progresso, da máquina, da velocidade, estando, pois, em consonância com o entusiasmo advindo da revolução industrial.

6 Sobre a relação entre velocidade, política e sociedade, ver VIRILIO, 1977.

\begin{tabular}{|c|c|c|c|c|}
\hline Rovista Oialectus & Ano 9 & n. 17 & Maio - Agosto 2020 & p.39-50 \\
\hline
\end{tabular}


panóptico $^{7}$. Uma das expressões mais evidentes desse controle pelo olhar se revela na singela e infame mensagem: sorria, você está sendo filmado!

É inegável que as conquistas da tecnologia continuam a gerar fascínio e a garantir os avanços materiais que melhoraram a vida da maior parte da humanidade. Apesar disso, elas não deixaram de suscitar preocupações existenciais e dilemas morais lancinantes. Tais inquietudes acabaram por ensejar a necessidade de se combater os avanços desordenados das ciências e de suas tecnologias por meio de Protocolos, Convenções, Resoluções, Declarações ou outros meios de disciplinamento normativo a fim de se evitar ou coibir suas práticas deletérias.

Nesse mesma perspectiva, tornou-se evidente a insuficiência da ética tradicional para conter a ação desordenada do homo tecnologicus no e sobre o mundo. Além disso, seria necessário criar outros esquemas teóricos ou instrumentos deontológicos para enfrentar os problemas postos pela democratização dos saberes, pelo pluralismo dos valores e pela secularização dos costumes. O desafio consistiria em orientar as ciências e seus instrumentos de atuação visando o respeito à vida e aos interesses humanos fundamentais por meio da negação do modo de vida mecanicista e da despersonalização do indivíduo no mundo sistêmico. Tal inquietude deu origem à bioética que surgiu não apenas como uma disciplina de interfaces, mas também como um novo campo de reflexão para o enfrentamento dessas encruzilhadas ${ }^{8}$.

Além das dificuldades acima indicadas, há inúmeros impasses e incertezas que emergiram junto com o avanço das biotecnologias e de sua presença cada vez mais acentuada na vida das pessoas e nos espaços naturais. Um desses desafios diz respeito à mudança do genótipo e suas repercussões psicossomáticas. De fato, tais eventos fizeram surgir alguns problemas referentes ao modo de estruturação da personalidade, gerando, por conseguinte, o que se poderia chamar de crise de identidade do sujeito.

7 Foucault utiliza esse termo inspirando-se no modelo de penitenciária ideal concebido, em 1785, por Jeremy Bentham, cuja estrutura das celas seria em círculo de modo que um único guardião, posicionado em seu centro, poderia vigiar todos os prisioneiros, sem que eles pudessem saber se estariam ou não sendo observados. E esta dúvida faria com que eles se comportassem devidamente.

8 A bioética como disciplina e campo de reflexão surge no início dos anos 1970 e traduz a necessidade de se responder aos dilemas que o progresso técnico-científico impôs às sociedades contemporâneas. A partir dela, visa-se instituir limites normativos à atuação dos operadores científicos. Desse modo, seus domínios de preocupação traduzem as exigências decorrentes do emprego de tecnologias e de práticas científicas de enormes repercussões, bem como dos problemas daí decorrentes. Sobre a bioética e seus princípios, ver BEAUCHAMP; CHILDRESS, 2002.

\begin{tabular}{|c|c|c|c|c|}
\hline Rovista Dialectus & Ano 9 & n. 17 & Maio - Agosto 2020 & p.39-50 \\
\hline
\end{tabular}


Parece inquestionável o fato de que vivemos na era do artifício, do in vitro, de modo que a reprodução humana tende a tornar-se uma questão de zootecnia ${ }^{9}$. O ser humano, embora ainda continue a ser naturalmente concebido, agora pode ser também "fabricado". Assim, não são poucas as críticas endereçadas aos perigos que a triagem genética de embriões pode engendrar, a exemplo da purificação étnica ou da produção de seres pretensamente superiores em sua constituição natural. Há ainda o perigo da padronização estética ou da busca de um modelo de perfeição humana. Ora, sabemos que o fascínio do belo pode se transformar em fascismo do belo. Além disso, a bioficção nos permite indagar: e se a ciência fizer da monstruosidade o seu ideal de humanidade?

Diante da ação desmesurada da potência tecnocientífica, alguns denunciam a crise do nosso modelo de civilização, baseado no controle e no domínio da natureza, cujas principais repercussões são as seguintes: devastação, catástrofes e acidentes naturais, poluição ambiental, variações climáticas, fatores geradores de uma profunda crise ecológica que tem colocado em xeque grande parte das conquistas advindas desse progresso.

Um outro problema consiste em saber como é possível, em face dessas mudanças radicais, aplacar a náusea existencial do indivíduo (cf. SARTRE, 2019) ou superar o mal-estar da nossa civilização (cf. FREUD, 2016). Em outras palavras, temos que enfrentar questões do tipo: qual o preço que devemos pagar pela vertiginosa marcha das ciências? Paralelamente ao progresso das ciências, estamos também progredindo moralmente? É mesmo admirável esse mundo novo? Como criar o melhor dos mundos e colocar nele o melhor dos homens? Finalmente, que tipo de morada estamos construindo para nós e para as futuras gerações?

Como sabemos, não há respostas fáceis para tais indagações, pois os problemas morais e, notadamente, os dilemas deônticos que deles decorrem, não encontram respostas no seio da cultura científica em que nascem. Eis por que não se pode fundar a ética em bases científicas. A essência do bem escapa ao campo de investigação da razão instrumental, pois o domínio do ser (objeto da ciência) não pode dar conta da esfera do dever-ser (universo da ética). O fato é que nem tudo que é cientificamente possível é humanamente desejável.

\footnotetext{
9 Esta nova modalidade de "criar" vida em laboratório envolve combinação gênica, reconfiguração de estruturas cromossômicas, procriação clinicamente assistida, dentre outros elementos. Porém, discute-se bastante sobre, por exemplo, o que fazer com os embriões excedentes nas clínicas de fecundação in vitro e também se a infecundidade é uma doença ou um evento natural. O fato é que tais procedimentos suscitam importantes questões bioéticas. Sobre isso, ver: CALLAHAN, 1970.
}

\begin{tabular}{|l|l|l|l|l|}
\hline Q Rovista Dialectus & Ano 9 & n. 17 & Maio - Agosto 2020 & p.39-50 \\
\hline
\end{tabular}


Assim, para alguns autores, o maior progresso que poderíamos legar à humanidade seria eliminar a própria ideia de progresso. Todavia, o progresso é mais do que uma ideia. Trata-se, talvez, de uma vocação ou ainda do resultado de uma força natural de propulsão da humanidade em direção ao melhor. Por conseguinte, negar ou coibir a marcha irrefreável da tecnociência é uma pretensão ingênua, pois não se pode eliminar da consciência da humanidade o desejo de progresso material. Aliás, como dizia Hume (2001), é sempre difícil silenciar o barulho dos grandes apetites e das infinitas ambições, uma vez que os homens são também regidos pela necessidade de maximizar o prazer e minimizar a dor. A razão, nesse caso, é escrava das paixões.

É claro que não convém transformar nossos fracassos em triunfo, mas, da mesma forma, não devemos nos confinar numa espécie de sinistrose apocalíptica e colocar o ser humano no banco dos réus, acusando-o de autor de todas as desgraças do Planeta, como se fosse um Prometeu pós-moderno. O fato é que devemos fugir do maniqueísmo e das simplificações que tão somente banalizam o problema. Afinal, nem todo cientista é um partidário incondicional do progresso que age regido por uma ideia fixa de destruição, uma espécie de Dr. Fausto, como no romance de Goethe (1964), pronto a vender sua alma ao diabo. Por conseguinte, nem os cientistas são necessariamente seres malignos, insensíveis, desumanos, nem, tampouco, convém condenar as ciências ou a tecnologia em nome de uma concepção primitiva segundo a qual o homem era feliz quando vivia nas savanas africanas fugindo de todas as ameaças e enfrentando seus inimigos com um tacape nas mãos.

A ciência não deve estar em julgamento, mas, quiçá, o modo como ela é utilizada, aplicada. Ou seja, convém denunciar seus desvios e deformações, jamais sua essência ou natureza. Ademais, o combate às suas anomalias não deve servir de motivação ao obscurantismo ou ao discurso raivoso de algum saudosista do atraso. Até porque, como dizia Sartre (1984), não importa o que se fez do homem, mas o que iremos fazer com o que fizeram dele. Por isso, de nada vale apenas acusar a tecnocracia e seus métodos ou condenar os interesses mercantis que embalam as descobertas científicas. Devemos estar aptos a aceitar o diagnóstico de Walter Benjamin (1987), segundo o qual todo monumento de civilização traz também as marcas da barbárie.

Além disso, estamos sempre à mercê do imponderável, do imprevisível, até porque, como sugeria Paul Valéry (1957), dois perigos mortais ameaçam a humanidade: a ordem e a desordem. Afinal, quem está disposto a, de forma consciente e deliberada, abdicar dos inegáveis avanços e conquistas proporcionados por todo aparato técnico-científico? Não

\begin{tabular}{|l|l|l|l|l|}
\hline Q Rovista Dialectus & Ano 9 & n. 17 & Maio - Agosto 2020 & p.39-50 \\
\hline
\end{tabular}


podemos viver em um mundo asséptico, livre de negações e mazelas. O acidente, ou a sua possibilidade, é o preço que pagamos pelo progresso tecnológico que usufruímos. É certo que devemos atenuá-lo, arrefecê-lo, e até mesmo, se possível, suprimi-lo, instituindo a aliança entre o saber, a convicção moral e a liberdade responsável. E, sobretudo, fazer do homem a medida de todas as coisas (Protágoras, 480-410 a.C.) ou um fim em si mesmo (Kant, 1980).

Todavia, talvez seja adequado pensar que os males da tecnologia só podem ser combativos com...mais tecnologia. Afinal, a tecnociência que polui é a mesma que cria filtros antipoluentes; a que produz motosserras também cria os satélites que identificam o desmatamento; o automóvel que mata é o mesmo que permite nosso deslocamento e encurta distâncias; o telefone celular que oprime também pode fomentar formas livres de viver. Isso indica que a modernidade nos legou, por meio das tecnociências, o bem e o mal, ou, ainda, os males e seus remédios. Acerca disso, vale lembrar a famosa ideia de Molière que, no século XVII, já afirmava em sua célebre peça $O$ doente imaginário (1973), que a pressa em obter o diagnóstico faz com que muitos homens morram de seus remédios e não de suas doenças.

\section{REFERENCIAS}

ADORNO, Theodor W; HORKHEIMER, Max. Dialética do esclarecimento. Rio de Janeiro: Zahar Editores, 1985.

ARISTÓTELES. Ética a Nicômaco, Brasília: Editora da UnB, 2001. Política (Obras Completas) Buenos Aires: Aguillar, 1982.

ASSIS, Machado de. Quincas Borba, São Paulo: Ática, 1982.

BAUDRILLARD, Jean. La société de consommation. Paris: Gallimard, 1970.

BEAUCHAMP; Tom L; CHILDRESS, James F. Princípios de ética biomédica. São Paulo: Loyola, 2002.

BENJAMIN, Walter. Magia e técnica, arte e política. Ensaios sobre literatura e história da cultura. In: Obras escolhidas. Vol. 1. São Paulo: Brasiliense, 1987.

CALLAHAN, David. L'éthique biomédicale aujourd'hui. In: Éthique et biologie, Cahiers STS, Paris, p, 46 a 59, 1970.

FOUCAULT, Michel. Surveiller et punir. Paris: Éditions Gallimard, 1975.

FREUD, Sigmund. O mal-estar na civilização. São Paulo: Companhia das Letras, 2016.

\begin{tabular}{|l|l|l|l|l|}
\hline Qevista Dialectus & Ano 9 & n. 17 & Maio - Agosto 2020 & p.39-50 \\
\hline
\end{tabular}


GOETHE, Johann Wolfgang. Fausto. Rio de Janeiro: Editora Letras e Artes, 1964.

HABERMAS, Jürgen. Técnica e ciência enquanto ideologia. São Paulo: Abril Cultural, 1980.

HUME, David. Tratado na natureza humana, São Paulo: UNESP, 2001.

KANT, Immanuel. Fundamentação da metafísica dos costumes. Lisboa: Edições 70, 1980.

LADRIÈRE, Jean. Ética e pensamento científico. São Paulo: Editora Letras \& Letras, 1984.

MARCUSE, Herbert. A ideologia da sociedade industrial: o homem unidimensional. Rio de Janeiro: Zahar, 1982.

MOLIÈRE. Le malade imaginaire. Paris: Le Petits Classiques Larousse, 1973.

PLATÃO. A República. São Paulo: Editora Lafonte, 2017.

Eutidemo. Rio de Janeiro: Edições Loyola, 2011.

POST, S. G. (Ed.). Encyclopedia of bioethics. New York: Prentice Hall, 2004.

\section{RABELAIS, François. Gargatua et Pantagruel. Paris: Editions du Rameau, 1950.}

ROUANET, Sérgio Paulo. As razões do Iluminismo. São Paulo: Cia. das Letras, 1987.

SARTRE, Jean-Paul. A náusea. Rio de Janeiro: Nova Fronteira, 2019.

. O existencialismo é um humanismo. São Paulo: Abril Cultural, 1984.

WEBER, Max. A ciência como vocação. In: Ensaios de Sociologia. Rio de Janeiro: Zahar, 1982. p. 154-183.

Letras, 2004.

A ética protestante e "espírito" do capitalismo. São Paulo: Companhia das

VALÉRY, Paul. Études Philosophiques. In : Oeuvres I (Collection Plêiade), Paris: Gallimard, 1957.

VIRILIO, Paul. Vitesse et politique: essai de dromologie. Paris: Editions Galilée, 1977.

\begin{tabular}{|l|l|l|l|l|}
\hline Govista Dialectus & Ano 9 & n. 17 & Maio - Agosto 2020 & p.39-50 \\
\hline
\end{tabular}




\begin{tabular}{|c|c|c|c|c|}
\hline Q Rovista Dialectus & Ano 9 & n. 17 & Maio - Agosto 2020 & p.39-50 \\
\hline
\end{tabular}

